\title{
Letztes Angebot
}

\author{
B. Gurtner
}

Ja, er meint es ernst, blutig ernst, todernst muss man wohl sagen. Sonst würde ich Sie nicht mitten in der Nacht anrufen. Sie haben doch Oberarztdienst? Er möchte mit dem Chef persönlich sprechen. Als Assistentin bin ich ...

... etwa 28 Jahre alt, schätze ich. Warten Sie, das Aufnahmeformular hat er schliesslich doch noch ausgefüllt. Zuerst wollte er uns seine Personalien nicht verraten. Hier: 23. November 1971. Mensch, der hat ja heute seinen - vielmehr gestern - seinen 30. Geburtstag! Jetzt wird mir ...

Nein, sonst wirkt er völlig besonnen. Der Mann ist fast unheimlich ruhig, aber zum Letzten entschlossen. Wenn wir ihm nicht sofort helfen - so, wie er es sich vorstellt -, wenn wir ihm nicht unverzüglich eine tödliche Spritze geben, geht er weg und bringt sich selber um.

Das habe ich jetzt über eine Stunde lang versucht, mit allen Argumenten. Dabei warten noch zwei andere Notfälle. Aber er bleibt stur bei seiner Meinung. Wir sollen ...

... ein Betrunkener für eine Wundversorgung - Messerstich am Vorderarm - und eine Türkin mit ihrem brüllenden Säugling ...

Ja, sagte ich schon. Wir sollen ihm zu einem anständigen und schmerzlosen Tod verhelfen. Sonst sei er gezwungen, sich auf die Geleise unter einen Zug zu werfen ...

... oh doch, Güterzüge, denke ich, fahren die ganze Nacht hindurch ...

... oder rast mit seinem Auto gegen einen Baum ...

... ein Sprung von der Brücke macht ihn ... Gewiss, auch damit hat er gedroht. Dabei würden alle seine gesunden Organe zerstört, die er lieber jenen schenken möchte, für die das Leben noch einen Sinn habe.

Doch, er hat da ganz klare Vorstellungen: Zwei Nieren, das Herz, die Lungen, die Leber, die Bauchspeicheldrüse, Blutgefässe, die Hornhaut der Augen und alles, was uns sonst noch an Ersatzteilen interessieren würde.

Ersatzteile hat er gesagt. Und natürlich kennen Sie die Anatomie. Entschuldigung!

Oh, der ist körperlich kerngesund, sportlich, bisher nie ernsthaft krank, wahrscheinlich Nichtraucher, riecht jedenfalls nicht nach Nikotin. Aber eben psychisch scheint es ihm ... seelisch muss da ...
Das würde er sofort. Er wäre sogar bereit, mit seiner Unterschrift zu bestätigen, dass er freiwillig und nach ... nach reiflicher Überlegung aus dem Leben scheiden wolle und alle Organe bedürftigen Patienten spenden möchte.

Eine Art Abschiedsgeschenk, kann man wohl sagen. Auch für Patientinnen, hoffe ich.

Nein, bis morgen früh will er nicht warten, er drängt auf einen sofortigen Entscheid, jetzt, subito. Deshalb habe ich mir ja erlaubt, Sie aus dem Schlaf zu reissen. Wenn wir nein sagen, will er wissen, wer dafür die Verantwortung übernimmt.

Doch, aber er kam auch nicht weiter. Die hochakute Suizidgefahr wurde bestätigt. Das war uns aber schon vorher klar. Der aufgeweckte Psychiater hat auch nicht realisiert, dass der Mann gestern seinen Gebur ...

... wie bitte?

... genau, kommt doch vor, oder?

Er empfiehlt sofortige Einweisung auf eine geschlossene Abteilung, nötigenfalls mit ...

Nein, die Polizei habe ich bisher nicht alarmiert. Müssen wir?

Aber gewiss, das habe ich dem Mann mehrmals zu erklären versucht. Er meint aber, dass die Chirurgen sehr gerne für eine so ergiebige Operation ins Spital kämen, jederzeit, auch nachts um zwei ...

Wir hätten doch alle Möglichkeiten, die Organe frisch zu halten, bis die Empfänger aufgeboten seien. Der stellt sich vor, wir könnten alles im Tiefkühlfach lagern.

Er muss das irgendwo in einer Zeitung gelesen haben. In China würden sogar Exekutionen auf Bestellung ausgeführt, um dringlich benötigte frische Nieren zu erhalten.

Ich glaube nicht, dass er sich noch lange hinhalten und vertrösten lässt. Er durchschaut solche Tricks. Doch wenn Sie meinen, könnte ich ...

... schon zu spät! Die Notfallschwester bedeutet mir eben, dass unser Mann in die Nacht davongelaufen ist. Der kommt nicht wieder. Schade um seine gesunden Organe, jammerschade um sein gutes Herz.

Meinen Sie? Für die Ethikkommission? Das wäre aber schwierig zu regeln. Sie kennen ja die Juristen und unsere ...

Ganz bestimmt, das denke ich auch. Also, Entschuldigung nochmals, und gute Nacht! 